\title{
Estimation of Power Spectral Density in SVPWM based Induction Motor Drives
}

\author{
V.Ananthalakshmi,Y.Rama Mohan, G.Sateesh, T.Bramhananda Reddy, A.Pradeep Kumar \\ Yadav
}

\begin{abstract}
This paper is readied the product programming of the SVPWM and half of breed PWM basically based DTC of recognition engine manipulate for assessing the strength Spectral Density (PSD) and the overall consonant mutilation (THD) of the road flows. The PWM set of guidelines utilizes three beautiful PWM methodologies like traditional SVPWM, $A Z P W M 3$ and combination PWM for the evaluation of the vitality spectra and consonant spectra. In quality spectra appraisal the extents of the power accrued at express frequencies and inside the consonant spectra the problem band sizes at one among a type replacing frequencies are taken into consideration for the assessment. To confirm the PWM calculations, numerical activity is performed making use of MATLAB/simulink Telugu (తెలుగు) is one of the Dravidian languages which is morphologically rich. As in the other languages it too contains polysemous words which have different meanings in different contexts. There are several language models exist to solve the word sense disambiguation problem with respect to each language like English, Chinese, Hindi and Kannada etc. The proposed method gives a solution for the word sense disambiguation problem with the help of $n$ gram technique which has given good results in many other languages. The methodology mentioned in this paper finds the co-occurrence words of target polysemous word and we call them as n-grams. A Telugu corpus sent as input for training phase to find n-gram joint probabilities. By considering these joint probabilities the target polysemous word will be assigned a correct sense in testing phase. We evaluate the proposed method on some polysemous Telugu nouns and verbs. The methodology proposed gives the F-measure 0.94 when tested on Telugu corpus collected from CIIL, various news papers and story books.The present methodology can give better results with increase in size of training corpus and in future we plan to evaluate it on all words not only nouns and verbs.
\end{abstract}

Key words: HPWM, Power Spectral Density, Total Harmonic Distortion.

\section{INTRODUCTION}

A awesome development inside the air conditioner drives is completed with the development in the dynamic execution of the PWM inverter. With this development primary troubles like bearing flows, breakdown of engine protection are taking place. those issues are raised due to the common Mode Voltage (CMV). Muach advancement has been made for diminishing the CMV. This development causes the overweight and quantity of the inverter which can not be maintained a strategic distance from [1]. The normal DTC is having lackluster showing because of the numerous confinements. subsequently, to reduce those impediments options must be explored. The exceptional SVPWM calculations proposed to diminish

Revised Manuscript Received on July 18, 2019

V.Ananthalakshmi, AP, India(E-mail:. v.al@rediffmail.com)

Y.Rama Mohan, AP, India

G.Sateesh, AP, India

T.Bramhananda Reddy, AP, India

A.Pradeep Kumar Yadav , AP, India the everyday mode voltages by way of growing the powerful exchanging occasions with the dynamic voltage vectors simply [2]. Thusly, with the recombination of the dynamic voltage vectors exceptional PWMs like AZPWM calculations are proposed. A drawback with those AZPWM calculations is high relentless nation swell [2]. on this paper, execution exam of 3 PWMs normal SVPWM, AZPWM3 and half of breed PWM strategies is completed with the help of the power spectra, symphonious spectra and the CMV styles of the every PWM.

\section{CONVENTIONAL SVPWM}

On this PWM, the reference voltage area vector (Vref)is determined [2].In Fig 1 the compelling heartbeat width of each degree is regarded. those heartbeats are obtained without having any modifications. The modified heartbeats are gotten which can be appeared in Fig 2 .

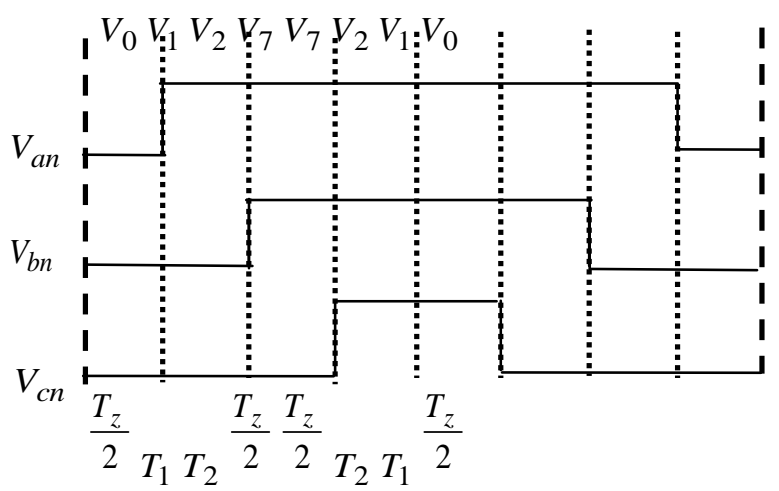

Fig.1PWM waveform and switching patterns of Conventional SVPWM technique

\section{AZPWM SEQUENCES \& RESULTS}

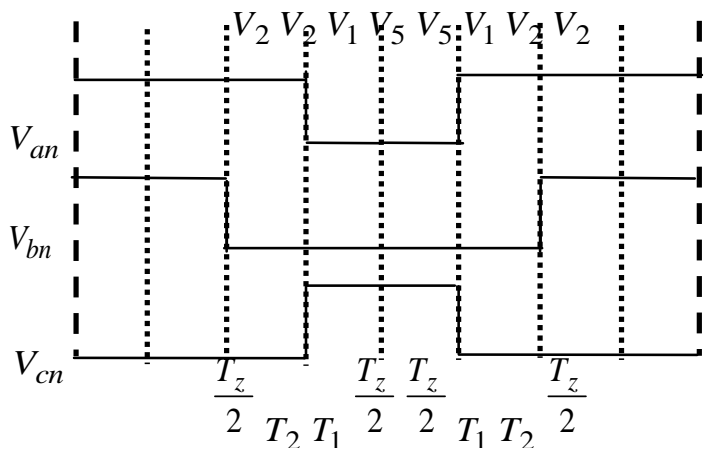

Fig.2 PWM waveform and switching pattern of proposed AZSPWM3 technique in sector-I. 
As SVPWM makes use of zero voltage vectors in every region CMV bureaucracy are severe. that allows you to lessen CMV types great AZPWM methodologies are mulled over with the utilization of nonexistent exchanging instances concept. From [2], it's far presumed that a large variety of the three groupings of AZPWM1, AZPWM2 and AZPWM3, AZPWM3 has higher widespread in wellknown execution. The changing successions in every territory for AZPWM3 method nearby feature normal SVPWM are regarded in work location I.This demonstrates that there may be an substantial reduce value in CMV varieties the use of AZPWM3 accumulation [2]. combination PWM primarily based DTC set of rules

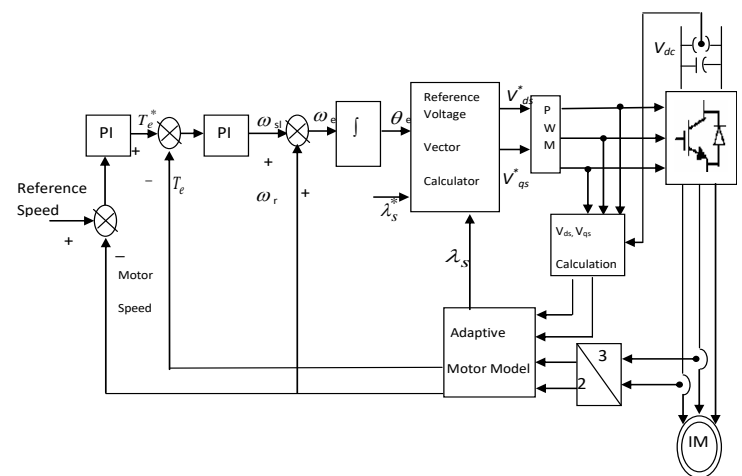

Fig.3. Block diagram of HPWM based DTC of IM drive

Table-I:- Switching sequences of AZPWM3 and Conventional SVPWM

\begin{tabular}{|c|c|c|c|c|c|c|}
\hline $\begin{array}{c}\text { PWM } \\
\text { MET }\end{array}$ & S-I & S-II & S-III & S-IV & S-V & S-VI \\
HOD & & & & & & \\
\hline CSVP & $0127-$ & $0327-$ & $0347-$ & $0547-$ & $0567-$ & $0167-$ \\
WM & 7210 & 7230 & 7430 & 7450 & 7650 & 7610 \\
\hline AZP & $2215-$ & $3326-$ & $4431-$ & $5542-$ & $6653-$ & $1164-$ \\
WM3 & 5122 & 6233 & 1344 & 2455 & 3566 & 4611 \\
\hline
\end{tabular}

Schematic graph for the Hybrid PWM set of proposals is probably discovered in Fig. three, this is pursued from the conventional DTC. an awful lot similar to the customary DTC the D-pivot and Q-hub voltages are gotten from the attitude and stator transition vector. The determined $\mathrm{D}$ and $\mathrm{Q}$ voltages than nourished to the appropriate PWM hinder for this case the PWM rectangular is walking basically depending on the Hybrid PWM set of recommendations. The created voltages from the PWM are then sustained to the voltage deliver inverter. [2].

\section{CONSEQUENCES AND DISCOURSE}

For the duplicate work of artwork, acceptance engine parameters are filed in [2] are notion approximately. the overall execution of the enlistment engine strain with three one in the whole lot about kind PWMs is shown in Fig.four - Fig.16. The front line swells for the three groupings are constructed up in Fig.4 - Fig. 6. those swells are obtained inside the heading of the everyday u.s. interest of the strain. For the social occasion 0127 and 2215 the modern-day swell is having the noteworthiness round $\pm 0.8 \mathrm{~A}$, anyway the shape within the gift swell is $\pm 1 \mathrm{~A}$ for half of breed PWM.

The power ghostly thickness for the three arrangements is affirmed in Fig. 7 - Fig. nine. The sizes of the satisfactory amassed on the exchanging recurrence zero. $1 \mathrm{kHz}$ is

Suitable anyway in 0127 association this characteristics is a excellent deal considerably much less than +10 $\mathrm{dB} / \mathrm{Hz}$ severe splendid however in 0127 accumulation this traits is hundreds bounty a dreadful part significantly much less than $+10 \mathrm{~dB} / \mathrm{Hz}$

In which as in stand-out successions the extents are in excess of $+10 \mathrm{~dB} / \mathrm{Hz}$. besides it can seen that the quit crests at one-of-a-type replacing frequencies are absolutely exorbitant even as test with the 0127 accumulation.

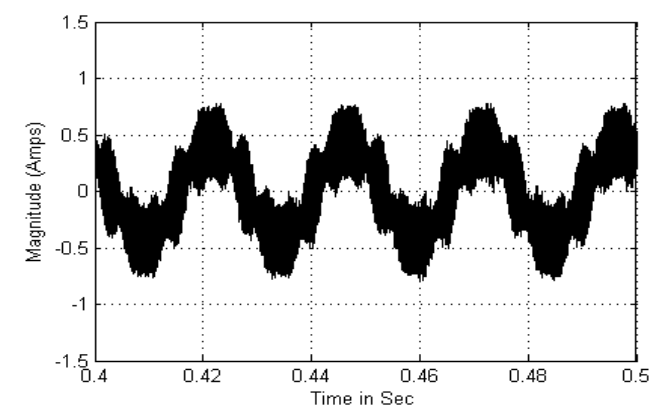

Fig.4. Motor line current ripple for 0127 sequence

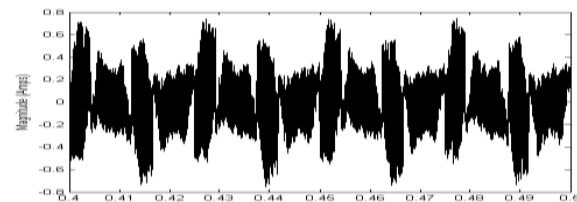

Fig.5. Motor line current ripple for 2215 sequence

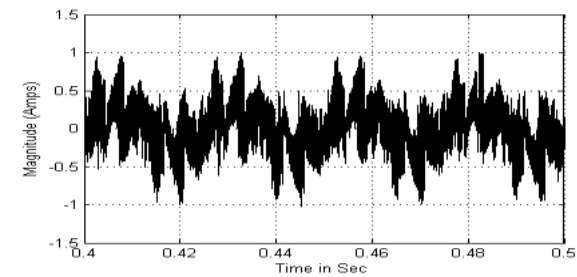

Fig.6. Motor line current ripple for HPWM

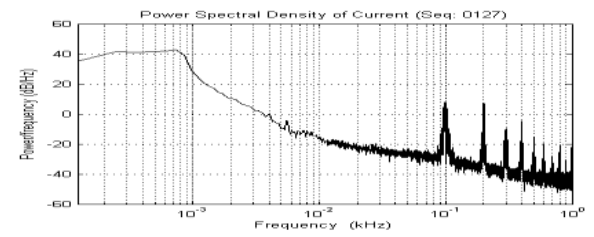

Fig.7. Motor line current Power spectra for 0127 sequence 


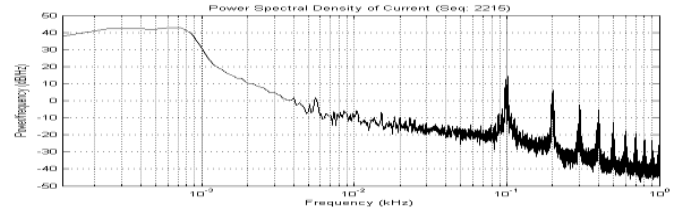

Fig.8. Motor line current Power spectra for 2215 sequence

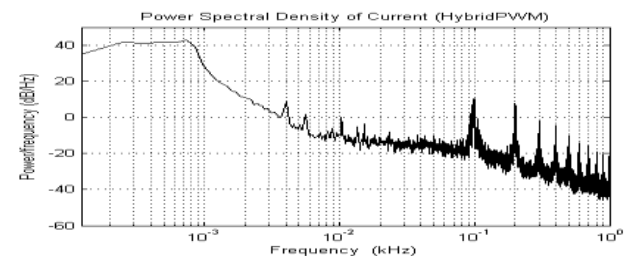

Fig.9. Motor line current Power spectra for HPWM

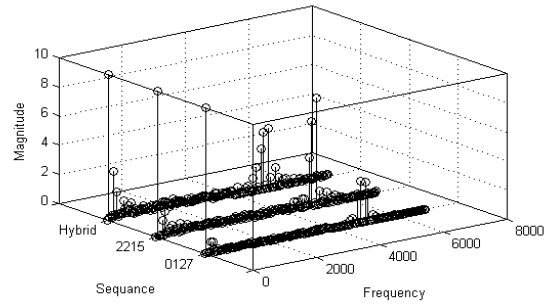

Fig.10. Total Harmonic spectra of the three PWM sequences.
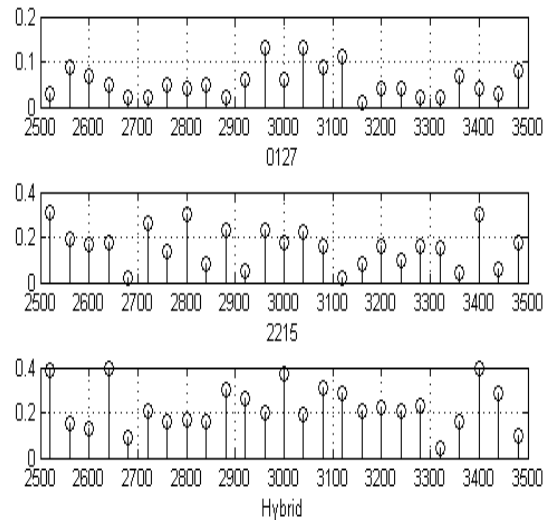

Fig.11. Harmonic spectra of the three PWM sequences with switching frequency $3 \mathrm{kHz}$.

The entire harmonic distortion of the motor line currents for the 3 sequences is examined in Fig.10. The THD is plotted for the 3 sequences from $0 \mathrm{~Hz}$ to $7000 \mathrm{~Hz}$ switching operations. The magnitudes of the harmonic content material material cloth cloth material at particular frequencies are validated. it's miles determined that the magnitudes of the harmonics are very an entire lot a whole lot much less extensively from the important problem. Later, on the inverter switching frequency that is spherical five $\mathrm{kHz}$ the magnitudes of the harmonic problem is considerably excessive.
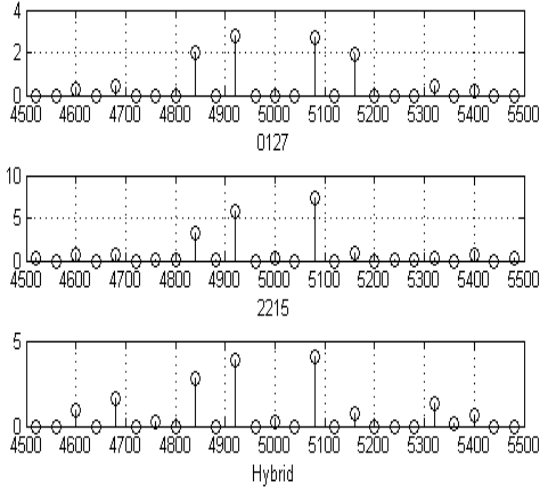

Fig.12. Harmonic spectra of the three PWM methods with switching frequency $5 \mathrm{kHz}$
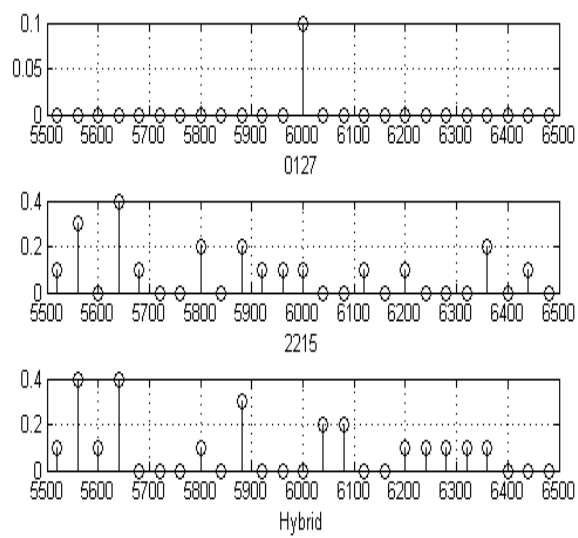

Fig.13. Harmonic spectra of the three PWM methods with switching frequency $6 \mathrm{kHz}$

What's greater, to explore the symphonious extents at eminent frequencies the consonant spectra of the engine line flows of 3 replacing successions is attempted in Fig.11 - Fig.13. In Fig.11, the consonant spectra of the road flows at $3 \mathrm{kHz}$ changing recurrence is portrayed. The apex insight recommends the symphonious spectra of the street modern-day-day of the reputation engine for the social occasion 0127, consciousness observe demonstrates the consonant spectra of the road the front line day-day of the enlistment engine for the get-together 2215 and rear observe demonstrates the symphonious spectra of the road present day-day-day of the enlistment engine for the crossover PWM individually. The noteworthiness of the symphonious at $3 \mathrm{kHz}$ is the base for the accumulation 0127 . With the replacing recurrence of $5 \mathrm{kHz}$ the extents are pretty much zero for most people of the 3 preparations but the hassle companies are approximately $\pm 100 \mathrm{~Hz}$ most for 2215 collecting. In Fig. 13 the consonant spectra of the road modern of the enlistment engine is delineated for $6 \mathrm{kHz}$ exchanging interest. At this changing activity, the value is the fairly large for 0127 accumulation and it is situated that the factor companies of the recurrence( $\mathrm{fs} \pm 1$ ) for the 2215 association and half of breed PWM is the base. 


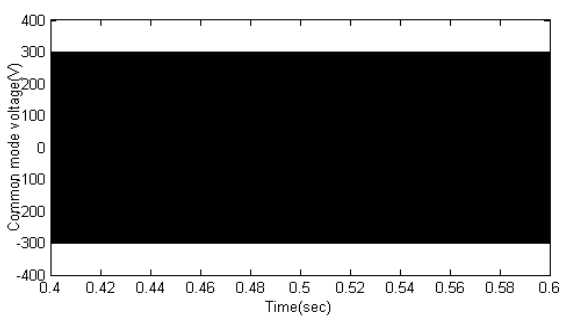

Fig 14 Common mode voltage variations in Conventional SV PWM based DTC

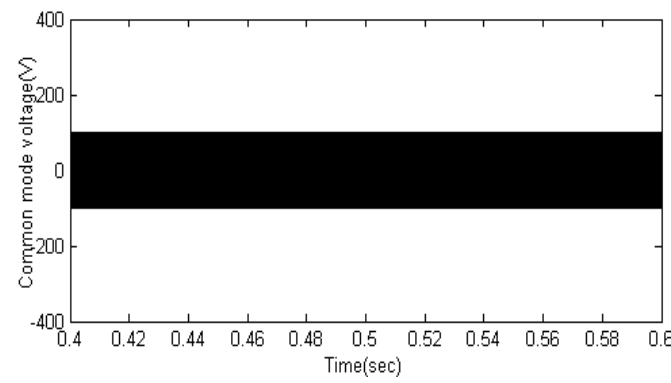

Fig 15 Common mode voltage variations in AZPWM3 based DTC

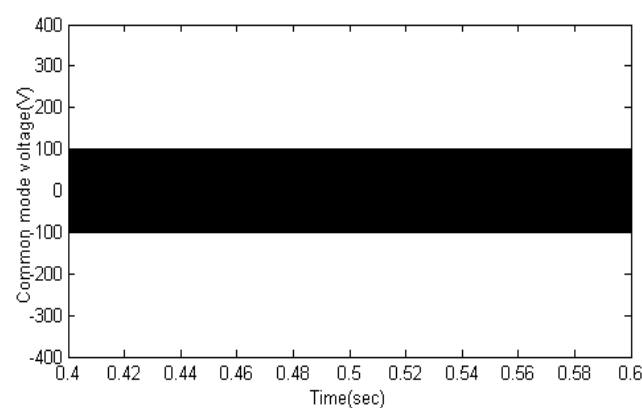

Fig 16 Common mode voltage variations in HybridPWM based DTC

While considering the CMV as shown in Fig.14 CMV is high $( \pm 300 \mathrm{~V})$ for 0127 sequence and it is the lowest $( \pm 100 \mathrm{~V})$ for 2215 sequence and hybrid PWM as shown in Fig. 15 and Fig.16.

\section{CONCLUSIONS}

In this paper everyday in general execution of preparations 0127, 2215 and combination PWM primarily based DTC of enlistment engine fine is feasible. the majority of the three successions are dissected with PSD, THD and CMV of the engine line flows with amazing frequencies. The electricity range of the engine line flows for the association 2215 is broadly better whilst in appraisal with 0127 gathering and half of and 1/2 PWM. In consonant spectra of the engine line flows, the essentialness of the music on the changing recurrence is basically radical if there should get up an occurrence of 2215 sequence. CMV types for 2215 sequence and move breed PWM is the base on the indistinguishable time as in assessment with 0127 association.

\section{REFERENCES}

1. Ogasawara, H.Ayano, and H.Akagi, "A functioning circuit for abrogation of regular - mode voltage produced via a PWM inverter," IEEETrans. power Electron., vol. 13, no.five,pp. 835-841, Sep. 1998.
2. Dr. V.Anantha Lakshmi, Dr. G.Satheesh, Dr. T.Bramhananda Reddy, M.Nayeemuddin, "SVPWM primarily based calculations for lower of commonplace Mode Voltage in Induction Motor Drives",worldwide journal of applied Engineering studies, Vol.12, No.1, August 2017. 